\title{
Envanter Yönetimi ve Uzantıları: Ekonomik Üretim Miktarı Modelleri Üzerine Bir Bilimsel Yazın Araştırması
}

\author{
Inventory Management and Extensions: A Review of Economic \\ Production Quantity Models
}

\author{
Yrd. Doç. Dr. Erdal Aydemir
}

\section{Öz}

Ekonomik Üretim Miktarı (Ë̈M) modellerinde, ne zaman ne kadar (miktar) üretim yapılacağı sorusuna cevap aranmaktadır. EÜM modelleri farkh varsayımlar altında araștırma güncelliğini korumaktadır. Bu çalışmada, ulusal ve uluslararası indeksler taranarak elde edilen bilimsel yazın örnekleri ile envanter yönetimi ve ekonomik üretim miktarı modellerinde yaşanan değişim süreci araştırılmaktadır. Özellikle 2000 yılı ve sonrasında üretim süreçlerinden kaynaklanan stoksuzluk, talebi sonradan karşılama, kusurlu ürünlerin üretimi, kalite kontrol ve kontrol hatalar, öğrenme etkisi, finansal etkiler vb. durumlar ve belirsizliklerin modellendiği görülmektedir. Böylece geliştirilen modellerin gerçek üretim ortamlarını daha iyi ifade ettiği düşünülmektedir. Günümüzde ise, EÜM modellerinde yaklaşımların olasılık, bulanık mantık, gri sistem teorisi ve sezgisel yöntemlerle desteklenme yoluna gidildiği bilimsel yazından açıkça görülmektedir. Ayrıca sonuç kısmında endüstri uygulayıcılarına ve araștırmacılara EÜM modelleri üzerinde dinamik, alıcl-satıcı, dış kaynak kullanımı, sipariş iptalleri, acil siparişler, envanter dağıtımı, geri dönüşüm parçalar ile kapalı-döngü tedarik içeren modeller yeni çalş̧ma alanları olarak gösterilmiştir.

Anahtar Kelimeler: Ekonomik Üretim Miktarı Modelleri, Stoksuzluk, Kusurlu Üretim

\begin{abstract}
Economic Production Quantity (EPQ) models search two important questions which are how much and when have to produce. The research on EPQ models is still important for many industries under different assumptions on EPQ models. In this paper, the scientific literature of the inventory management and its extensions where is mostly liked for EPQ models are mentioned with historical review by using national and international databases with indexes. The shortages, backordering, imperfect items, quality control and errors, learning curves, financial effects, and uncertainties are mostly seen in this research area for modeling on classical EPQ from the literature since 2000. Thus, we think that the real life problems are well defined by these proposed models. Today, the modelling of the stochastic, fuzzy logic, grey system theory and metaheuristics methods are used for large scale EPQ models. However, in the conclusion of this paper, for industrial practitioners and researchers the new research areas are discussed and presented which are dynamic, vendor-buyer, outsourcing, cancellation of orders, emergency orders, inventory routing, recycling process and close-loop supply chains for EPQ models.
\end{abstract}

Keywords: Economic Production Quantity Models, Shortages, Imperfect Production 


\section{Giriş}

Giderek artan rekabet koşulları altında işletmeler faaliyetlerine devam edebilmek için müşteri ihtiyaçları ve beklentilerine hızlı cevap verebilecek esnekliğe sahip olmak zorundadırlar. Özellikle farklı sipariş alma şekillerinin geliştiği günümüzde hızlı ve doğru teslim kabiliyeti gibi belirleyici faktörler ön plana çımaktadır. Günümüzde en kısa zaman diliminde ulaştırma hizmetlerini gerçekleştirebilecek yapıdaki tedarik zinciri yönetim sisteminin önemi, stratejik bir araç haline gelmektedir. Bu çevikliği sağlayabilecek sistemin ve sürecin sürdürülebilir olabilmesi için envanter yönetimi ve kontrolü son derece önemlidir. Genellikle envanter seviyesinin belirlenmesi ve kontrolü sürecinde toplam maliyeti enküçükleme ya da toplam kârı enbüyükleme amacına ulaştıracak sipariş ve/veya üretim miktarı ve bunun ne zaman gerçekleştirileceği sorularına cevap aranmaktadır.

Genel olarak işletmeler açısından envanter türleri; hammadde, yarı mamul, yardımcı malzeme stokları ve nihai ürünler şeklinde ele alınmaktadır. Bunun yanı sıra bir stok kalemi için talep miktarı, müşteri tarafından belirleniyorsa stoklar bağımsız ya da başka bir parçanın stok miktarına göre belirleniyor ise bağımlı talep stokları olarak sınıflandırılır. İşletmeler ayrıca talep, tedarik süresi ve işletme arzı gibi sistemde ortaya çıkan belirsizliklerden olumsuz etkilenmemek için emniyet stokları bulundurmayı tercih ederler. Gerek Ekonomik Sipariş Miktarı (ESM) gerekse Ekonomik Üretim Miktarı (EÜM) modelleri talep karakteristiği göz önüne alınarak da sınıflandırılmaktadır. Talep biliniyorsa model deterministik (belirli) envanter modeli olarak isimlendirilirken talep yapisı rassal bir özellik gösteriyorsa ve/veya belirli bir olas1lık dağılımı ile ifade edilebiliyorsa olasılıklı (stokastik) model olarak ele alınmaktadır. Stokastik modeller aynı zamanda belirsizlik içermesi yönüyle gerçek uygulama problemlerinin önemli bir olgusunu ele alması nedeniyle de önemlidir (Kumar ve Suresh, 2008; Nahmias, 2009; Yüksel, 2010; Yenersoy, 2011).

Stok kontrolü için bilimsel gelişim süreci, Harris (1913) tarafından ESM problemi ile başlatılmıştır. EÜM modelleri açısından bilimsel yazında yayınlanan ilk model toplam envanter maliyetlerinin enküçüklenmesine yardımcı olan ve Taft (1918) tarafından önerilen modeldir. Birçok endüstriyel sistemde uygulama alanı bulan EÜM modelleri ilerleyen zaman içinde, hazırlık maliyetleri, elde bulundurma maliyet- leri, talep ve üretim oranları başta olmak üzere model girdisini oluşturan parametrelerin ve/veya değişkenlerin gerçekçi olmayan varsayımlarının ortadan kaldırılması amacıyla modele eklenmiştir.

Envanter yönetimi ve modelleri üzerine yapılan bilimsel yazın taraması çalışmalarında; daha özelleşmiş konulara göre yapıldığı görülmektedir. Rafaat (1991) yaptığı çalışma sürekli fiziksel değişim gösteren ürünleri, Ben-Daya vd. (2008) ekonomik parti büyüklüğü, ve Pentico ve Drake (2011) ise EÜM modellerinde sonradan kısmi karşılama durumlarını ele almışlardır. Sulak ve Eroğlu (2009) ise, ESM ve EÜM modelleri için yeni açllımlardan bahsetmişler. Bu çalışma ile, Sulak ve Eroğlu (2009) çalışmasının doldurduğu boşluk özellikle son beş yıldaki değişimi de içerecek şekilde genişletilmiştir.

Araştırmanın temel konusu olan EÜM modellerinin, bilimsel süreçteki gelişimi ile endüstriyel gelişime göre izlediği yolları ortaya koymak ise çalışmanın temel amacını ve gerekliliğini ifade etmektedir. Çalışmanın ikinci bölümünde envanter yönetimi kısminda; envanter, envanter kontrolü, envanter maliyet türleri ve işletmelerin envanter bulundurma nedenleri konuları ele alınmaktadır. Üçüncü bölümde ise, ekonomik üretim miktarı modeli kısmında; klasik ekonomik üretim miktarı modelinin bileşenleri ve matematiksel modeli detaylıca gösterilmektedir. Çalışmanın dördüncü bölümü, yapılan bilimsel yazın araştırmasının yöntemini içermektedir. Bu kısımda, taranan indeksler, anahtar kelimeler ve yöntemin EÜM modelleri açısından öneminden bahsedilmektedir. Beşinci bölüm olan bulgular bölümünde ise, EÜM modellerinin değişim ve gelişim süreci bilimsel yazın örnekleri ile desteklenerek konularına göre sınıflandırılmaktadır. Çalışmanın son bölümünde, EÜM modellerinin varsayımlarının günümüz üretim sistemleri ve modellerine cevap verebilmesi için hangi alanlarda geliştirilebileceği ve gelecek araştırması için bilimsel yazındaki boşluklar ve yeni araştırma alanları sunulmaktadır.

\section{Envanter Yönetimi}

Genel olarak işletmelerde envanter düzeyinin takip edilmesi, hangi seviyelerde sürdürüleceğine ve stokların ne zaman yenilenmesi gerektiğine karar verilmesi ve sipariş/üretim miktarlarının belirlenmesi fonksiyonları bir envanter (stok) yönetim sistemi ile 
sağlanabilmektedir (Monks, 1996; Kobu, 2006; Nahmias, 2009; Yüksel, 2010). Envanter yönetim sistemlerinde temel amaç, ihtiyaç duyulan parçanın istenilen miktarda istenilen zamanda ve istenilen yerde hazır bulunmasını sağlamaktır. Bu amaca hizmet edecek envanter kontrol sistemleri; işletme/organizasyon yapısı, ürün yapısı, yönetim yaklaşımları gibi unsurlara bağlı olarak farklılıklar göstermektedir.

Genel olarak envanter kontrol yöntemleri ve uygulamaları şu şekilde sınıflandırılmaktadır (Kobu, 2006; Schuh, 2006; Kumar ve Suresh, 2008; Nahmias, 2009; Yüksel, 2010; Yenersoy, 2011):

İşletme deposunda yer alan stoklar tecrübeli bir depo sorumlusu tarafindan periyodik olarak gözden geçirilir. Buna Gözle Kontrol Yöntemi adı verilmektedir. Stoklanan malzemeler, kaba bir şekilde iki kısma ayrılmakta ve birinci kutudaki malzeme bittiği anda, iki kutunun toplam kapasitesi kadar malzeme siparişi verilerek, tedarik süresi tamamlanıncaya kadar geçen sürede ihtiyaç ikinci kutudan karşılanır. Bu yönteme ise Çift Kutu Yöntemi denilmektedir. Bu yöntemler günümüz işletmeleri için pratik olarak gözükse de kaba yöntemler olarak değerlendirilmektedir.

Günümüzde ise işletmeler için ürün-üretici-tüketici boyutlarının ve çeşitliğinin artması nedeniyle arztalep belirsizliği bulunmaktadır. Bu durumda farklı kontrol ve izleme politikaları gelişmektedir. Her defasında verilen sipariş miktarı sabit, fakat sipariş verme süreleri farklı ise Sürekli Gözden Geçirme Yöntemi tercih edilir (Şekil 1a). Bu sistemde, stok miktarı belirli bir seviyenin altına indiğinde, toplam stok maliyetini minimum yapmak için yeni bir sipariş verilmektedir. Ayrıca, sipariş verme süreleri sabit iken sipariş miktarları farklılık gösterdiği duruma ise Periyodik Gözden Geçirme Yöntemi adı verilen sistem kullanılır (Şekil 1b). Uygulamada yeniden sipariş verilirken sipariş miktarı, önceden tanımlanmış bir hedef stok seviyesine göre belirlenmekte ve bu yöntemde de hedef stok seviyesi ve sipariş verme süresinin ne olacağının belirlenmesi önemli hale gelmektedir. Her iki durum Şekil 1 olarak gösterilmiştir (Yenersoy, 2011).

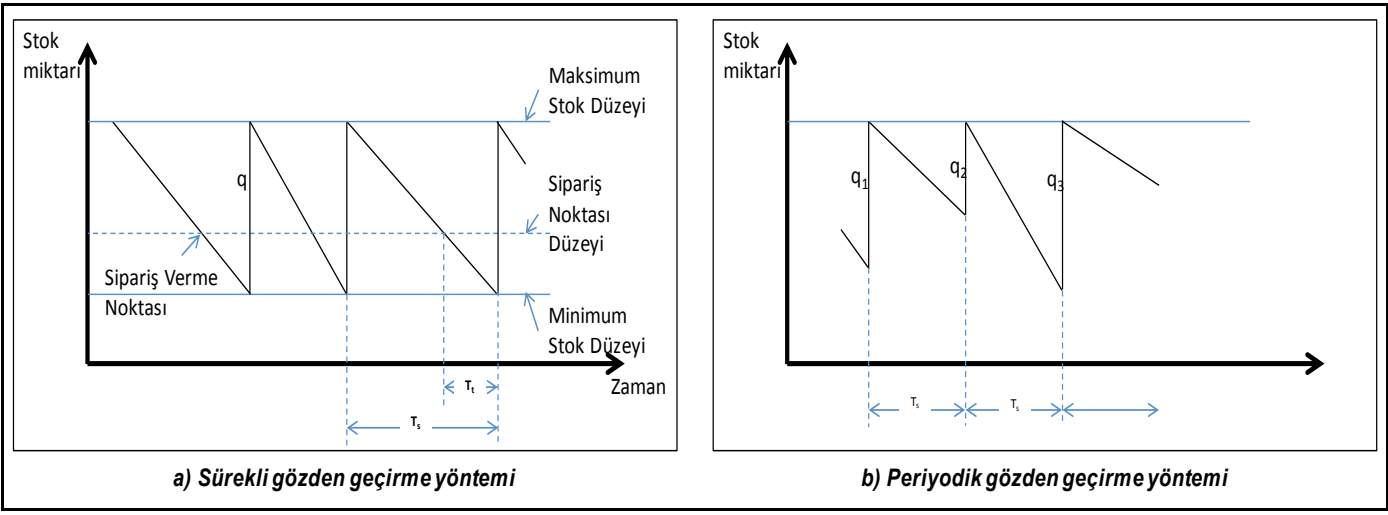

Şekil 1. Sürekli ve Periyodik Gözden Geçirme Yöntemleri

Stokta bulunan parçaların envanter değerlerinin (stokların parasal karşıllı̆ı) göreli önem sıralamasına göre izlenmesine $A B C$ analizi adı verilmektedir. $\mathrm{Bu}-$ rada A sınıfı parçalar en yüksek ve $C$ sınıfı ise en düşük göreli envanter değerine sahip parçaları temsil etmektedir. Ayrıca, üretim için gerekli olan bu parçaların kullanım şekillerine göre de değerlendirilmesi söz konusudur. Bu izafi değerlendirmeye ise Kritik Değer Analizi (XYZ Analizi) adı verilmektedir. Burada X “düzenli", Y "salınımlı" ve Z "düzensiz" kullanılan ya da ihtiyaç duyulan parçaları ifade etmektedir. Başka bir ifade ile, X sınıfı parçalar stoksuzluğuna izin verilemeyecek düzeyde kritik, Y sınıfı parçalar için belirli miktarda stok tutulan ve belirli miktarda stoksuzluğa izin verilebilen ve $Z$ sınıfı parçalar ise stoksuzluğuna izin verilebilen daha az göreli öneme sahip veya önemsiz olabilecek parçaları anlamına gelmektedir. $\mathrm{ABC}$ analizi ve XYZ kritik değer analizi bütünleşik olarak da değerlendirilebilir. Böylece dokuz farklı stok tutma politikası elde edilebilir. Tablo 1'de bu bü- 
tünleşik yapı gösterilmektedir. Örneğin; $A X$ tipindeki parçalar miktar olarak az olmalarına rağmen envanter değeri yüksek olan, düzenli tedarik gerektiren ve stoksuzluğuna izin verilmeyecek kritik parçalar olarak sinıflandirılmaktadır.

Tablo 1. ABC-XYZ Bütünleşik Analizi

\begin{tabular}{cccc}
\hline & $\boldsymbol{X}$ & $\boldsymbol{Y}$ & $\boldsymbol{Z}$ \\
\hline $\boldsymbol{A}$ & $A X$ & $A Y$ & $A Z$ \\
$\boldsymbol{B}$ & $B X$ & $B Y$ & $B Z$ \\
$\boldsymbol{C}$ & $C X$ & $C Y$ & $C Z$ \\
\hline
\end{tabular}

Gelişen teknolojinin envanter kontrolü ve izleme sistemleri açısından da etkileri bulunmaktadır. Bilgisayar yardımıyla sadece stokları miktar olarak takip etmenin yanısıra envanter bilgisi; barkod, çubuk kod (iz) ve/veya karekod şeklinde her çeşit ürün için benzersiz olarak tanımlanan bir kimliklendirme yöntemiyle de takip edilebilmektedir. Optik okuyucular barkod/ka- rekod bilgisi sisteme eklenebilmektedir. Günümüzde radyo frekansı (RF) özelliğinin kullanılarak daha etkin bir şekilde stok miktarı kontrolü kablosuz olarak, koli/paket içleri, raflar, depolama alanlarına araçların giriş çıkışları dâhil olmak üzere birçok fonksiyon çok etkin bir şekilde yapılabilmektedir.

Stok modelleri, sipariş verme/üretim yapma kararlarını alabilmek için uygun miktar ve zamanın belirlenmesini sağlamak üzere sistem için birim zamanda toplam maliyeti enküçüklemeye çalışan bir eniyileme (optimizasyon) yaklaşımı olarak ele alınabilmektedir. Burada toplam maliyet fonksiyonu Şekil 2'de gösterilmektedir. Şekil 2'ye göre birim zamanda toplam maliyet fonksiyonun en küçük olduğu noktada ESM modeli için optimum sipariş miktarı $\left(\mathrm{Q}^{*}\right)$ ve EÜM modeli için optimum üretim miktarı $\left(\mathrm{Q}^{*}\right)$ değerleri hesaplanmakta ve toplam maliyet ise; üretim/sipariş hazırlık, satın-alma/üretim, elde bulundurma ve/ veya elde bulundurmama maliyetlerinin toplamindan oluşmaktadır.

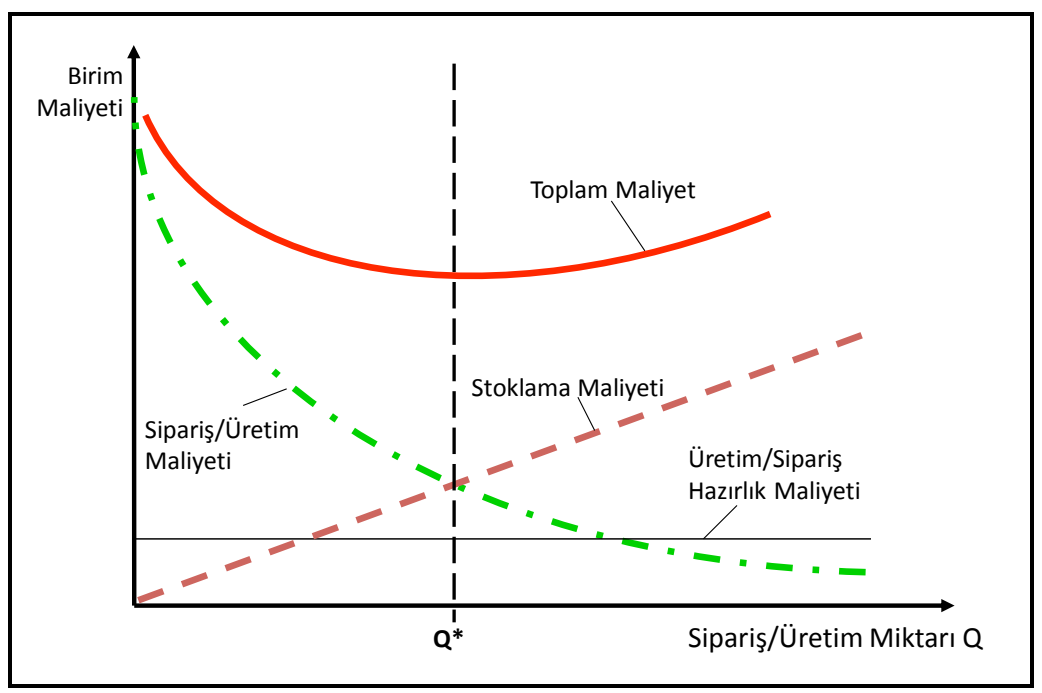

Şekil 2. Sipariş/Üretim Miktarı Toplam Maliyet Fonksiyonu 
$\mathrm{Bu}$ durumda envanter maliyetleri ise aşağıdaki şekilde sınıflandırılabilir (Tersine, 1994; Eroğlu, 2002; Nahmias, 2009; Yenersoy, 2011):

- Sipariş/üretim hazırlık maliyeti (çevrim başına)

- Satın-alma/üretim (değişken) maliyeti (birim başına)

- Elde bulundurma maliyeti (birim başına)

- Depolama maliyeti

- Sermaye maliyeti

- Sigorta ve vergi maliyetleri

- Bozulma, eskime ve fire maliyetleri

- Sistem maliyetleri

- Elde bulundurmama maliyeti (birim başına)

- Stok dişı kalma (stoksuzluk) maliyeti, kaçırılmış olan satışlar ve kârlar, müşteri memnuniyetsizliği, üretim aksamasından dolayı gecikmeler, teslim zamanının kaçırılması sonucu ödenen cezalar ve talebin sonradan karşılanması için yapılacak olan ek işletme giderlerini (haberleşme, üretim, yeniden işleme, kargo, nakliye, vb.) de kapsar.

- Yeniden işleme maliyeti (birim başına)

Geliştirilen ESM/EÜM modelleri ile birim zamanda toplam maliyeti en küçüklemeye çalışan işletmeler çeşitli nedenlerle stok tutmayı ve/veya stok için üretim yapmayı tercih ederler. İşletmeler açısından stok tutmaya ilişkin gerekçeler ise genel olarak aşağıdaki gibidir (Kumar ve Suresh, 2008; Nahmias, 2009):

- Ekonomik Ölçekler: Birim maliyetleri ve hazırlık zamanlarını azaltmak için büyük partiler ile çalışma isteği ortaya çıabilir.

- Belirsizlikler: En önemli belirsizlik talep dalgalanmaları ile ortaya çıkan durumdur. Çünkü üretim sistemlerinin en temel tetikleyicisi talep miktarıdır. Buna karşın işletmenin bu talebe karşı arz belirsizliği de önemlidir.

- Spekülasyonlar: Bir parça ya da doğal bir kaynağın değerinin yükselmesi yönündeki beklentiler ya da spekülasyonlar, ilgili parçanın ekonomik değerinin artmasına ve ona harcanan sermayenin yükselmesine neden olmaktadir.
- Taşıma/Ulaştırma: Öncelikle deniz aşırı ve/veya kıtalararası faaliyetleri bulunan işletmeler, büyük ölçekli stoklar tutmak ve ulaştırmalar yapmak durumundadır. $\mathrm{Bu}$ nedenle, işletme açısından bu işlemler hem büyük bir maliyet hem de zaman alıcı bir unsurdur.

- Lojistik: Müşteri ihtiyaçlarını karşılamak üzere her türlü ürünün (mamul/servis), üretim kaynaklarından son müşteriye teslim edilene kadar geçen tüm süreçlerde; satın alma, üretim ve dağıtım gibi süreçlerin devamlıllğının stoklar ile sürdürülmesini içermektedir.

- Düzgünleştirme: Bir ürün için talepte meydan gelen değişim belirli (deterministik) ya da rassal olabilir. Belirli değişim durumu için sezon etkisi, rassal değişime ise ekonomik şartlarda meydana gelen beklenmedik değişimler örnek verilebilir. Doğal olarak bu değişimler üretim oranlarının ve işgücü seviyelerinin değişmesine de neden olabilir. Bu farklardan etkilenmemek için düzgünleştirme (smoothing) tekniği kullanılarak, maliyetler ile beklenen dalgalanmaları dengeleyecek planlamalar yapılabilir. Bu değişimlere tepki olarak işletmeler stok tutabilirler.

- Kontrol Maliyetleri: Stok kontrol sisteminin sürdürülme maliyeti yani farklı parçalar için farklı minimum stok seviyelerinin dikkate alınmasını gerektiren durumlarda ortaya çıkan maliyet türüdür. En önemli maliyet kalemlerinden biri olmasına rağmen sıklıkla gözden kaçırılan da bir faktör olabilmektedir.

\section{Ekonomik Üretim Miktarı Modeli}

Klasik EÜM modeli, optimal üretim miktarı kadar üretim yapılacağı gerçeğini ortaya koyar. Bu modelin temel varsayımları aşağıdaki gibidir (Eroğlu, 2002):

- Talep ve üretim hızı sabittir.

- Üretim hızı, talep hızından büyüktür.

- Üretim hazırlık maliyeti sabit ve bilinmektedir.

- Birim üretim maliyeti ve elde bulundurma maliyetleri sabit ve bilinmektedir.

$\mathrm{Bu}$ temel varsayımlar çok genel bir yaklaşımı içermektedir. Klasik EÜM modeli bu noktada model çevrim süresi boyunca iki kısımda ele alınmalıdır (Şekil 3). Birinci aşamada üretim yapılarak talep karşılanır ve talep fazlası stok olarak biriktirilir, ikinci aşamada ise üretim yapılmaz ve talep birinci aşama sonunda üretimle biriktirilmiş olan stoktan dönem sonuna kadar karşılanır. Dönem sonunda stok düzeyi tamamen eritilir. (Eroğlu, 2002). 


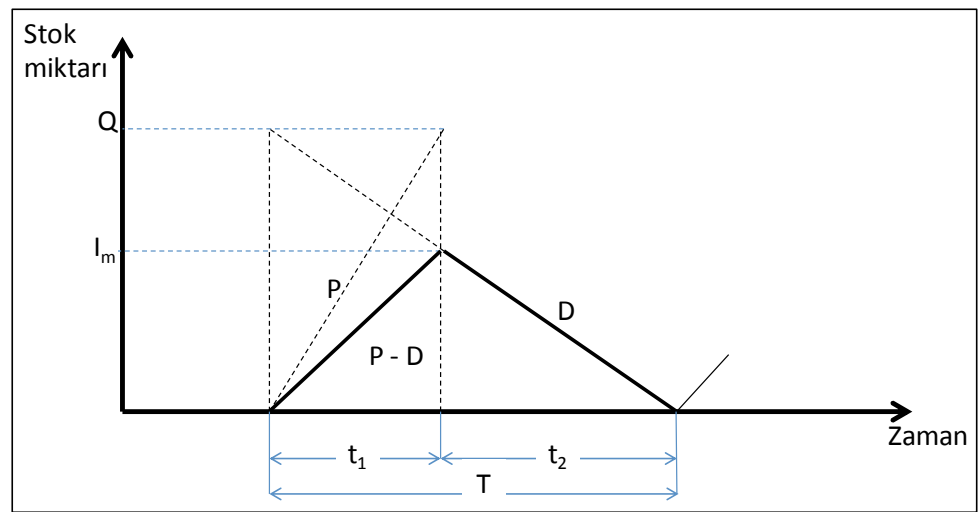

Şekil 3. EÜM Modeli İ̧in Çevrim Boyunca Stok Değişimi

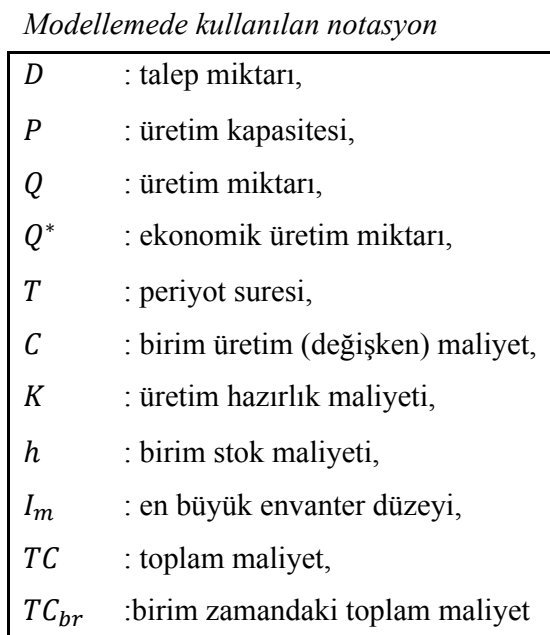

Şekil 3’te verilen EÜM modeli için toplam maliyet denklemini aşağıdaki gibi yazılabilir:

$$
\begin{gathered}
t_{1}=\frac{I_{m}}{P-D}=\frac{Q}{P} \\
t_{2}=\frac{I_{m}}{D} \\
T=\frac{Q}{D} \\
T=t_{1}+t_{2}
\end{gathered}
$$

ise bir periyottaki maksimum stok miktarı

$I_{m}=\left(1-\frac{D}{P}\right) Q$

Toplam maliyet Fonksiyonu

$T=C Q+K+h \frac{I_{m}}{2} T$

Burada $\mathrm{I}_{\mathrm{m}}$ ve T yerine yazılırsa;

$T=C Q+K+h \frac{\left(1-\frac{D}{P}\right) Q^{2}}{2 D}$ 
Birim zamanda toplam maliyet fonksiyonu

$$
\begin{gathered}
T C_{b r}=\frac{T C}{T} \\
T C_{b r}=C D+K D+h \frac{\left(1-\frac{D}{P}\right) Q}{2}
\end{gathered}
$$

Eşitlik 9'da $Q$ (üretim miktarı) değişkenine göre türev alınır ve sıfıra eşitlenir böylece, kesin dışbükey bir fonksiyon olduğu bilinen, birim zamanda toplam maliyet fonksiyonunu (Şekil 2) en küçükleyecek olan ekonomik üretim miktarı $\left(Q^{*}\right)$ elde edilir.

$$
\begin{gathered}
\frac{d T C_{b r}}{d Q}=-\frac{K D}{Q^{2}}+\frac{h\left(1-\frac{D}{P}\right)}{2}=0 \\
\frac{K D}{Q^{2}}=\frac{h\left(1-\frac{D}{P}\right)}{2} \\
Q^{*}=\sqrt{\frac{2 K D}{h\left(1-\frac{D}{P}\right)}}
\end{gathered}
$$

EÜM modeline göre, her T zaman çevriminde $Q^{*}$ değeri kadar üretim yapılması gerekmektedir.

\section{Yöntem}

Bu çalışmada, araştırma yöntemi temelde bilimsel yazın taramasına dayanmaktadır. Ayrıca, EÜM modelleri için gelişen endüstriyel üretim modellerine göre ihtiyaç duyulan alanlar ve bilimsel yazındaki boşluklar tespit edilerek araştırmacıları bu alanlara teşvik etmek istenmektedir. Bu amaçla ilişkili olarak gerçekleştirilen bilimsel yazın taraması, Tablo 2'de verilen indeksler gerçekleştirilerek özellikle birbirini izleyen EÜM modellerindeki varsayımların yok edilmesiyle sağlanan gelişim süreci dikkate alan çalışmalar seçilmiştir.

EÜM modellerine yönelik çalışmalar için, stoksuzluk (shortage), kusurlu ürünler (imperfect items), yeniden işleme (rework), kalite kontrol (inspection errors, quality control etc.), talebi sonradan karşılama (backordering), öğrenme ve unutma etkisi (learning and forgetting effects), arıza-bakım (breakdown-maintenance), izleme/planlama periyodu (planning horizon), değişken talep (variable demand), değişken maliyet (variable costs), finansal durumlar (inflation, delay in payments, sales return etc.) ve yapay zeka teknikleri (fuzzy logic, genetic algorithms, grey systems

Tablo 2. Taranan Indeksler

\begin{tabular}{ll}
\hline Ulusal indeksler & Uluslararası indeksler \\
\hline Akademia Sosyal Bilimler Indeksi (ASOS Index) & Directory Open Access Journal (DOAJ) \\
Arastirmax- İndeks & EBSCO \\
Tübitak ULAKBIM & Engineering Index \\
Türkiye Makaleler Bibliyografyast & Google Scholar \\
& Science Citatiton Index (SCI) \\
& Science Citation Index- Expanded (SCI-E) \\
& Scopus \\
& Social Science Citatiton Index (SSSCI) \\
& Social Science Citation Index- Expanded (SSCI-E) \\
\hline
\end{tabular}

theory, particle swarm, swarm intelligence etc.) anahtar kelimeleri kullanılarak tarama yapılmıştır. Yine benzer şekilde Pentico ve Drake (2011) yaptıkları çalışma ile ESM ve EÜM modellerinde yaşanan geliştirmelerin \%90'ının 1990 yılı sonrası ve \%75'nin ise 2000 yılı sonrası gerçekleştirildiğini göstermişlerdir. $\mathrm{Bu}$ nedenle, özellikle 2000 yılı ve sonrasındaki gelişmelere ağırlık verilerek seçilen çalışmalar bulgular kısmında özetlenmiştir.

\section{Bulgular}

Bilimsel yazında, birçok araştırmacı ve endüstri çalışanı tarafından EÜM modelleri ile ilgili olarak makale, kitap ve teknik not şeklinde farklı modeller yayımlanmıştır. EÜM modelinin varsayımları gevşetilerek ve/veya yeni kısıtlar eklenerek gerçek hayat uygulamalarını daha iyi temsil etmeye yönelik yeni modeller geliştirilmiştir. Bu konudaki bilimsel yazın araştırması Tablo 3’te özetlenmiştir. 
Tablo 3. EÜM Modelleri Bilimsel Yazın Araştırması

\begin{tabular}{|c|c|}
\hline EÜM Modeli Kapsamı & Bilimsel Yazın \\
\hline Klasik model & Taft (1918) \\
\hline Stoksuzluk durumu ${ }^{1}$ & Chung ve Hou (2003) \\
\hline $\begin{array}{l}\text { Kusurlu ürünler ve } \\
\text { kalite kontrol }\end{array}$ & $\begin{array}{l}\text { Rosenblatt ve Lee (1986); Kim ve Hong (1999); Salameh ve Jaber (2000); Chung ve Hou (2003); } \\
\text { Chung ve Hou (2003); Ojha vd. (2007); Yoo vd. (2009); Sana (2010); Wee vd. (2013) }\end{array}$ \\
\hline Yeniden işleme & $\begin{array}{l}\text { Schrady (1967); Nahmias ve Rivera (1979); Richter (1996a); Richter (1996b); Richter (1997); } \\
\text { Teunter (2001); Hayek ve Salameh (2001); Chan vd. (2003); Dobos ve Richter (2003); Dobos ve } \\
\text { Richter (2004); Eroğlu vd. (2008); Taleizadeh vd. (2013); Pal vd. (2013); Glock ve Jaber (2013) }\end{array}$ \\
\hline $\begin{array}{l}\text { Talebin sonradan } \\
\text { karşılanma durumu }\end{array}$ & $\begin{array}{l}\text { Chiu (2003); Li vd. (2008); Pentico vd. (2009); Zhang (2009); Cheng vd. (2010); Drake vd. (2011); } \\
\text { Toews vd. (2011); Zhang vd. (2011); Stojkovska (2013) }\end{array}$ \\
\hline Öğrenme ve unutma etkisi & $\begin{array}{l}\text { Jaber ve Bonney (1998); Karaöz (2003); Ben-Daya ve Hariga (2003); Chui ve Chen (2005; Alamri } \\
\text { ve Balkhi (2007); Jaber ve Bonney (2007); Jaber vd. (2008), Jaber ve Guiffrida (2008); Jaber ve El } \\
\text { Saadany (2011); Mukhopadhyay ve Goswami, (2013) }\end{array}$ \\
\hline Arıza - bakım & $\begin{array}{l}\text { Nahmias ve Rivera (1979); Chiu vd. (2007); Chiu vd. (2007); Liao vd. (2009); Liao ve Sheu } \\
\text { (2011); Chiu vd. (2011); Wee ve Widyadana (2012) }\end{array}$ \\
\hline İzleme periyodu & Axsater (1993); Chen (1999); Ben-Daya vd. (2008); Hariga (2010); Yang vd. (2011) \\
\hline Değişken talep & $\begin{array}{l}\text { Balkhi ve Benkherouf (2004); Teng ve Chang (2005); Teng vd. (2005); Sana (2008); Sarkar vd. } \\
\text { (2011); Singh ve Singh (2011); Majumder ve Bera (2013); Dem vd. (2014) }\end{array}$ \\
\hline Değişken maliyetler & Bayındır vd. (2006); Bayındır vd. (2007); Darwish (2008); Ertoğral (2011) \\
\hline $\begin{array}{l}\text { Bulanık Mantık, } \\
\text { Gri Sistem Teorisi } \\
\text { Meta-sezgiseller }\end{array}$ & $\begin{array}{l}\text { Chang (2004); Chen vd. (2005); Islam ve Roy (2006); Zhao (2006); Pan ve Yang (2008); } \\
\text { Pasandideh ve Niaki (2008); Halim vd. (2009); Bhunia vd. (2009); Roy vd. (2009); Pal vd. (2009); } \\
\text { Mula vd. (2010); Kazemi vd. (2011); Köse vd. (2011); Björk (2012); Hafshejani vd. (2012); } \\
\text { Aydemir (2013) }\end{array}$ \\
\hline Finansal durumlar & $\begin{array}{l}\text { Hofmann (1988); Hariga ve Ben-Daya (1996); Chung (1998); Chung ve Huang (2003); Liao } \\
\text { (2007); Lo vd. (2007); Teng ve Chang (2009); Hu ve Liu (2010); Kreng ve Tan (2011); Mahata } \\
\text { (2012); Musa ve Sani (2012) }\end{array}$ \\
\hline
\end{tabular}

1913 yılında Harris tarafından sunulan "How Many Parts to Make at Once" -bir çevrimde kullanmak için ne kadar parça gereklidir- başlıklı makale ESM modelinin, 1918 yllinda Taft tarafından sunulan "The Most Economical Production Lot" -en ekonomik üretim partisi- başlıklı makale ise EÜM modelinin ilk bilimsel çalışmaları olarak kabul edilmektedir. Rosenblatt ve Lee (1986) tarafından geliştirilen EÜM modeli kusurlu ürünleri de içermekteydi. Modelde üretim süreci boyunca rassal değişken olarak ele alınan bir zaman noktasına (o ana) kadar üretilen ürünlerin tümünün kusursuz olduğu ve sistemin kontrol dış1na çıktığı ana kadar ki geçen sürenin üstel dağılıma uyduğu kabul edilmiştir. Aynı model, Kim ve Hong (1999) tarafından sistemin kontrol dışına çıktığı ana kadar ki geçen sürenin genel rassal dağılıma uyduğu kabulüyle genişletilmiştir. Daha sonra, Chung ve Hou (2003) tarafından ilgili modele stoksuzluğa izin

1 Stoksuzluk durumu sonradan geliştirilen birçok model içinde de sıklıkla yer alır. Bu nedenle bu konuyu detaylı bir şekilde ele almış olan çalışmalardan biri olan Chung ve Hou (2003) çalışmasına öncelikli olarak yer verilmiştir. verilmesi durumu eklenmiştir. Deterministik envanter modellerinde yeniden işleme ve/veya tamir süreci konusunda ilk model Schrady (1967) tarafindan geliştirilen model olarak kabul edilmektedir. Model ile en uygun üretim miktarı ve tamir edilebilir ürün miktarına karar verme konusunda çalıșılmıştır. Daha sonra bu model, sonlu ve belirli bir tamir oranına izin verecek şekilde Nahmias ve Rivera (1979) tarafından genişletilmiştir. Ayrıca, Schrady (1967) modelini, bir ESM modeli olarak durağan talep durumu (Richter, 1996a) ve ekonomik değişimleri içerecek durumu yansitan (Richter, 1996b), tamir edilebilir, tamir edilemez ve hurda/atık ürün durumunu (Richter, 1997) ve elde bulundurma maliyetini sağlam ve atık ürünlere göre farklılaştıran (Teunter, 2001) modeller geliştirilmiştir (Jaber ve Saadany, 2011).

Özellikle son on yılda, üretim ortamından kaynaklanan stoksuzluk durumları, talebin sonradan karşılanması, kusurlu ürünlerin üretimi, kalite kontrol ve kontrol hataları, öğrenme etkisi, ödemelerde gecikmelere izin verilmesi ve ticari kredi politikaları gibi 
belirsizlik nedenlerinin endüstriyel uygulamalarda kullanılan modellerde kullanıldığı görülmektedir (Salameh ve Jaber, 2000; Hayek ve Salameh, 2001; Bayındır vd., 2007; Liao, 2007; Darwish, 2008; Jaber vd., 2008; Pentico vd., 2009; Teng ve Chang, 2009; Mahata, 2012).

Sipariş verilen bir partinin kusurlu üretime sahip olduğu ve kusur oranının tekdüze (uniform) dağılıma uyduğunu kabul eden ESM modelinde stoksuzluğa izin verilmesi durumu ilk kez Salameh ve Jaber (2000) tarafindan sunuldu. Benzer durum, kusurlu ürünlerin üretimi konusunda; Hayek ve Salameh (2001) tarafından stoksuzluğa izin verilmesi, kusurlu ürünlerin tamamının yeniden işlenmesi yoluyla kusursuz hale getirilmesi ve yeniden işleme süresinin dikkate alınması şeklinde bir EÜM modeli olarak geliştirildi. Daha sonra, Chiu (2003) tarafından Hayek ve Salameh (2001) modeli, kusurlu ürünlerin belirli bir oranının yeniden işleme yoluyla kusursuz hale getirilmesi ve geriye kalan miktarın ise sskartaya ayrılması varsayımı ile genişletilmiştir. Ittharat (2004) tarafından stok maliyetleri ile kusurlu üretim sonucu ortaya çıkan kalitesizlik maliyetlerini dikkate alarak yıllık toplam maliyeti enküçükleyen bir matematiksel model geliştirilmiştir.

Chan vd. (2003) tarafından üretim süreci boyunca ürünler kusursuz ve kusurlu kabul edilen ürünler, düşük kalite düzeyinde kusursuz (indirimli satış fiyatı ile satılabilen), tamir edilebilecek kusursuz ve iskarta şeklinde üç farklı şekilde sınıflandırılmıştır. Geliştirilen modellerde stoksuzluk ve tamir süresi için herhangi bir süre ortaya konulmamıştır. Bu model, Eroğlu vd. (2008) tarafından stoksuzluğa izin veren ve tamir süresini içerecek şekilde iki farklı endüstriyel uygulama problemi ile desteklenerek sunulmuştur.

Chui (2008) ise, çevrim sonrası kusurlu ürünlerin hurda veya yeniden işlenebilir olmasının belirli bir kurala göre tespit edilmesini sağlayan EÜM modelini önermiştir. Modelde, yeniden işleme sürecine alınan her bir parça için birim tamir/yeniden işleme maliyetini mutlak kritik değer olarak hesaplayan etkin bir kural ortaya konulmuş ve örnek problemler ile gösterilmiştir. Sana (2010) ise, toplam üretim miktarının belirli bir yüzdesini üretim sürecinde sisteminin kontrol dışı kalarak kusurlu hale getirdiği varsayımıyla EÜM modeli geliştirmiştir. Modelde kusurlu ürünlerin yüzde olarak değeri, üretim oranı ve üretim süresine bağlı olarak türetilmiştir. Kontrol dışı süreç dikkate alındığında, üretim sürecini kontrol diyagramları ile takip eden bir EÜM modeli Pan vd. (2012) tarafından geliştirildi. Geliştirilen model, kalite kontrol diyagramları ile üretim süreci üzerinde örüntü aramayı kullanarak beklenen toplam üretim maliyetini her bir çevrim için enküçüklemeye çalışmaktadır. Ayrıca, kusurlu ürünler, yeniden işleme ve hurda ürünler varsayımlarının birkaçını aynı anda içeren modeller de geliştirilmiştir (Taleizadeh vd., 2013; Pal vd., 2013; Glock ve Jaber, 2013).

Kaçırılan siparişin planlı ya da bir kısmının sonradan karşılanması durumu EÜM modellerinin gelişme sürecinde ele alınan başka bir boyuttur. Planlanmış sonradan karşılama durumu (Li vd., 2008) ve kısmi karşılama durumu (Zhang, 2009; Pentico vd., 2009; Pentico vd.,2011; Drake vd., 2011; Toews vd., 2011; Stojkovska, 2013) bilimsel yazında yer alan çalışmalardır.

Öğrenme eğrisinin ESM/EÜM modellerinde ilk ele alındığı araştırma Keachie ve Fontana (1966) çalışması olarak kabul edilmektedir. EÜM modelleri üretim sürecini temsil eden ve öğrenme ile unutma etkisinden bahseden Jaber ve Bonney (1998) çalışması ön plana çıkmaktadır. Karaöz (2003) ise, öğrenme ve farklı talep fonksiyonlarının etkilerini yansıtan EÜM modelleri geliştirmiştir. Sonraki süreçte ise öğrenme etkisi içeren modellere bilimsel yazında daha fazla rastlanmaktadır (Ben-Daya ve Hariga, 2003; Chiu ve Chen, 2005; Alamri ve Balkhi, 2007; Jaber ve Bonney, 2007; Jaber ve Guiffrida, 2008).

Kusurlu ürün oranını azaltıcı yönde etkisi olacağı düşünülen bir öğrenme eğrisi Jaber vd. (2008) tarafından EÜM modellerine dâhil edilmiştir. Jaber vd., otomotiv sanayisinde karşılaşılan bir probleme uyarlanan EÜM modelinin sonucu olarak, öğrenmenin çevrim süresi sonunda kusurlu ürün üretim yüzdesini hızlı bir şekilde düşürdüğünü göstermişlerdir. Jaber ve Saadany (2011) tarafindan Dobos ve Richter (2003) ve Dobos ve Richter (2004) tersine lojistik yaklaşımı ile yeniden işleme/üretim ve atık ürünleri içeren modellerine öğrenme etkisinin eklenmesi ile yeni bir EÜM modeli önerilmiştir. Bu çalışmada ayrıca, öğrenme etkisinin ortaya konulması için sermaye yatırımının gerekliliği sayısal örneklerle gösterilmiştir. Benzer şekilde Mukhopadhyay ve Goswami (2013) ise yaptıkları çalışmada; öğrenme eğrisinin kusurlu ürünlere etkisini göstermek üzere tedarik zinciri sürecini dikkate alan bir model sunmuşlardır. 
EÜM modellerinde gerçek hayat problemlerine ait durumların modellenmesine katkı olarak ele alınan varsayımlar yok etme yöntemi ve/veya makine bozulmaları ve bakım durumudur. Chiu vd. (2007) tarafından makine bozulma durumlarını stokastik olarak EÜM modellerine yansitılmıştır. Daha sonra Liao vd. (2009) ile Liao ve Sheu (2011) tarafından yapılan çalışmalarla sırasıyla kusurlu üretim süreçleri için tamir ile bakım ve en az tamir oranı ile bakım durumlarını içeren EÜM modellerinin geliştirildiği görülmektedir. Cheng vd. (2010) stoklama zamanları için yeniden işleme ve makine bozulma ve durma süreçlerini içeren bir EÜM modeli; Chiu vd. (2011) ise, rassal makine bozulması sürecini belirli bir kusurlu oranı altında çözen matematiksel model önerdiler. Wee ve Widyadana (2012) ise yaptıkları çalışmada, EÜM modellerine bozulabilen (zamanla niteliği değişim gösterebilen) ürünler için olasılıklı önleyici bakım sürelerinde yeniden işleme sürecini eklemişlerdir.

Envanter modellerinde talep karakteristiği belirleyici bir özelliğe sahiptir. Talep karakteristiği üzerine yapılan çalışmalarda, talebin zamana ve/veya stok miktarına bağlı olarak değiştiği ve bulanık olarak ifade edildiği farklı durumların modelleri bilimsel yazında görülmektedir (Balkhi ve Benkherouf, 2004; Teng ve Chang, 2005; Teng vd., 2005; Sana, 2008; Sarkar vd., 2011; Singh ve Singh, 2011; Majumder ve Bera, 2013; Dem vd., 2014). Stok kontrol problemlerinin çözümü açısından önemli bir diğer olgu ise stokların takip edilmesi üzerine yapılan araştırmalardan oluşmaktadır. Talep belirsizliğinin bir olasılık dağılımı ile temsil edildiği durumları içeren ve olasılıklı stok modelleri olarak da bilinen modellerde sürekli gözden geçirme bir envanter izleme politikası olarak bilimsel yazında yer almaktadır (Axsater, 1993; Chen, 1999; Hariga, 2010; Yang vd., 2011). Alıcı-satıcı arasındaki alışveriş sonucu ortak parti büyüklüğünün belirlenmesi problemi literatürde ele alınan diğer bir konudur (Bayındir vd., 2006; Ben-Daya vd., 2008; Ertogral, 2011).

Özellikle son yıllarda gelişen bilgisayarlı hesaplama tekniklerinin de EÜM modellerinin çözümlenmesine katkılar sağladığı söylenebilir. Yapay zeka teknikleri ve modern sezgisel yöntemler ile EÜM modellerinin çözümüne ilişkin çalışmaya sınırlı sayıda da olsa literatürde rastlanılmaktadır. Chen vd. (2005) tarafından, farklı koşullar altında bulanık fırsat maliyetleri, yamuk üyelik fonksiyonuna sahip stok maliyetleri ve miktarlarını temel alan kusurlu ürünler için EÜM modeli geliştirilmiştir. Halim vd. (2009) ise, ağıllık merkezi yöntemi kullanan bulanık mantık yaklaşımı ile sürecin kontrol içinde/dışında olması durumunu vardiya belirsizlikleri ile modellemişlerdir. Benzer şekilde, bulanık talep ve kusurlu oranı (Chang, 2004; Mula vd., 2010), bulanık esneklik ve güvenilirlik (Islam ve Roy, 2006), bulanık üretim oranı (Pan ve Yang, 2008), yeniden işleme (Roy vd., 2009), talebin bulanıklaştırılmış karar değișkenleri/ parametreler ile sonradan karşılanması durumu (Kazemi vd., 2010) ve sonlu üretim oranı (Björk, 2012) için bulanık mantık kullanarak geliștirilen EÜM modelleri literatürde yer almaktadır. Ayrıca, polinom zamanlı çözümü olmayan ve kısmi çözümü olan problemlerin çözümünde sıklıkla tercih edilen sezgisel ve meta-sezgisel yöntemlerin de EÜM/ESM modellerinin analizinde tercih edildiği görülmektedir. Özellikle genetik algoritmalar ile yapılan çalışmalara sıklıkla rastlanılırken (Mondal ve Maiti, 2003; Pasandideh ve Niaki, 2008; Pal vd. 2009; Bhunia vd., 2009; Zhang vd., 2011; Hafshejani vd., 2012) parçacık sürüsü optimizasyonu kullanan sadece bir çalışmaya ulaşılabilmiştir (Zhao vd., 2006).

Deterministik EÜM modelleri bazı durumlarda eksik bilgiler içerebilir. Eksik bilgi ve/veya zamanında tamamlanamamış bilgi içeren sistemlerin modellenmesinde tercih edilmeye başlanan gri sistem teorisinin de etkin çözümler ürettiği literatürde ortaya konulmuştur. Köse vd. (2011) tarafından klasik ESM için geliştirilen gri modelde bulanık mantık karşısında sağlanan avantajlar gösterilmiştir. Benzer şekilde Aydemir (2013) tarafından EÜM modellerinin kusurlu ürünler, yeniden işleme ve hurda ürünler ile stoksuzluk durumları için gri sistem teorisi ile bir model geliştirilmiştir. Bu modelin gri talep ve maliyetler altında davranışı gerçek bir endüstriyel uygulama problemi ele alınarak analiz edilmiş ve modelin işleyişi ve elde edilen sonuçlar tartışılmıştır.

Envanter modelleri tarihsel gelişme sürecinde, finansman olgusunu ele alan modeller de geliştirilmiştir. Nakit akışlarına göre düzenlenmiş EÜM modeli (Hofmann, 1998), enflasyon etkisi (Hariga ve BenDaya, 1996; Lo vd., 2007), ödemelerde gecikmeye izin verilmesi (Chung, 1998; Chung ve Huang, 2003; Liao, 2007; Hu ve Liu, 2010; Musa ve Sani, 2012), satışların geri dönüşü (Yoo vd., 2009) ve ticari kredi politikalarını dikkate alan (Teng ve Chang, 2009; Kreng ve Tan, 2011; Mahata, 2012) çalışmalar da bilimsel yazında yer almaktadır. 


\section{Sonuç}

$\mathrm{Bu}$ çalışmada, üretim işletmeleri için önemli olan envanter modellerinin üretim ilişkilerini birlikte ele alan EÜM modellerinin önemli tarihsel gelişim süreci detaylı olarak incelenmiştir. Gerçekleştirilen bilimsel yazın taraması sadece EÜM ve uzantılarına ilişkin olarak yapılmıştır. EÜM modelleri içinde yer alan araştırma konularını aynı anda birkaçını birarada içeren çok sayıda çalışma bulunmasından dolayı bu araştırmanın en önemli kısıtı; atıf yapılan çalışmaların genellikle aynı anahtar kelime içinde birbirini izleyen zincir çalışmalardan seçilmiş olmasıdır. Ayrıca, seçilen araştırma makalelerinin lisansüstü tezler ve araştırma projelerinden türetilmiş olmasına dikkat edilmiştir. Bu sayede; elde edilen önemli sonuçlardan birisi, endüstriyel uygulamaları çözmeye yönelik model varsayımlarının giderek yok edilmeye başlanması olarak gösterilebilir. Klasik EÜM modeli dışbükey (konveks) eniyileme problemi olduğu kesin olarak bilinen ve toplam birim maliyet fonksiyonu üzerinde;

- stoksuzluk,

- talep ve maliyet değişkenliği,

- talebi sonradan karşılama,

- süreç sonunda elde edilen farkli tipte ve seviyede kusurlu ürünler,

- yeniden işleme,

- kalite kontrol ve kontrol hatalari,

- makine/teçhizat bozulmaları,

- finansal etkiler (enflasyon, satışların geri dönüşü, ödemelerde gecikmeler)

gibi genişletmeler ile yeni EÜM modelleri elde edilmektedir. Böylece geliştirilen modellerin endüstriyel problemleri daha iyi temsil etmeye çalıştığı düşünülmektedir. Bu modellerin daha karmaşık bir hal almasında, özellikle belirsizlik durumlarının olasılık, bulanı mantık, meta-sezgisel yöntemler, gri sistem teorisi gibi tekniklerle yönetilebildiği veya kontrol alt1na alındığı gözlenmiştir.

Araştırmacılar ve endüstriyel uygulamacıların tedarik zinciri süreci boyunca EÜM modellerini geliştirme kapsamında;

$$
\begin{aligned}
& \text { - dinamik parti büyüklüğ̈̈, } \\
& \text { - alıcı-satıcı sözleşmeleri, } \\
& \text { - dış kaynak kullanımı, }
\end{aligned}
$$

\author{
- üretim siparişlerinin iptali, \\ - üretim öncelikleri, \\ - ürün yapısı (stoklama sürecinde fiziksel değişim \\ gösterebilen ürünler), \\ - acil siparişlerin etkileri, \\ - envanter miktarının dağıtımı, \\ - geri dönüşüm, \\ - çok seviyeli tedarik zinciri \\ - kapalı-döngü tedarik zinciri,
}

gibi konulara yönelerek yeni modeller üzerinde yapacakları çalışmaların gerek bilimsel yazına gerekse endüstriye katkılar sağlayacağı düșünülmektedir. Bu yeni modellerin giderek karmaşık hale gelen endüstriyel ortamlar için varyasımları yok ederek ve belirsizlikleri modelleyerek deterministik koşullar başta olmak üzere daha fazla etkili olacak farklı çözümleri sunacağı öngörülmektedir. Sonuçta, bu çalışma, EÜM modelleri açısından bilimsel ve teorik gelişimin endüstriyel gelişimi temsil etme kabiliyeti ortaya koyma ve bu kabiliyeti yükseltmeyi sağlayacak yeni çalışma alanlarının tespit edilerek uygulayıcılara yol gösterme işlevini üstlenmektedir.

\section{Kaynakça}

Alamri, A. A., Balkhi, Z. T. (2007). The effects of learning and forgetting on the optimal production lot size for deteriorating items with time varying demand and deterioration rates. International Journal of Production Economics, 107 (1), 125-138.

Axsater, S. (1993). Continuous review policies for multi-level inventory systems with stochastic demand. In: Graves, S.C. (Ed.), Handbooks in Operations Research and Management Science, vol. 4. North Holland, Amsterdam, The Netherlands.

Aydemir, E. (2013). Kusurlu Ürünleri İçeren Ekonomik Üretim Miktarı Modelinin Gri Sistem Teorisi Yaklaşımıyla Geliştirilmesi: Endüstriyel Bir Araştırma. SDÜ FBE Makine Mühendisliği ABD, Yayımlanmamış Doktora Tezi, 202s.

Balkhi T. Z., Benkherouf L. (2004). On an inventory model for deteriorating items with stock dependent and time varying demand rates. Computers and Operations Research 31, 223-240. 
Bayındır, Z. P., Birbil, Ş. İ., Frenk, J. B. G. (2006). The joint replenishment problem with variable production costs. European Journal of Operational Research, 175, 622-640.

Bayındır, Z. P., Birbil, Ş. İ., Frenk, J. B. G. (2007). A deterministic inventory/production model with general inventory cost rate function and piecewise linear concave production costs. European Journal of Operational Research, 179, 114-123.

Ben-Daya, M., Darwish, M., Ertogral, K. (2008). Joint economic lot sizing problem; A review and extensions. European Journal of Operational Research, vol. 185/2, 726-742.

Ben-Daya, M., Hariga, M. A., (2003). Lead-Time Reduction in a Stochastic Inventory System with Learning Consideration. International Journal of Production Research, 41 (3), 571-579.

Bhunia, A. K., Kundu, S., Sannigrahi, T., Goyal, S. K. (2009). An application of tournament genetic algorithm in a marketing oriented economic production lot-size model for deteriorating items. International Journal of Production Economics, 119 (1), 112-121.

Björk, K.-M. (2012). A multi-item fuzzy economic production quantity problem with a finite production rate, International Journal of Production Economics, 135 (2), 702-707.

Chan, W. M., Ibrahim, R. N., Lochert, P. B. (2003). A new EPQ model: integrating lower pricing, rework and reject situations. Production Planning and Control, 14(7), 588-595.

Chang, H.-C. (2004). An application of fuzzy sets theory to the EOQ model with imperfect quality items. Computers and Operations Research, 31, 2079-2092.

Chen, F. (1999). On $(r, n Q)$ policies in serial inventory systems. In:Tayur,S., Ganeshan, R., Magazine, M.(Eds.), Quantitative Models for Supply Chain Management. Kluwer, Norwell, MA.

Chen, S. H., Wang, S. T., Chang, S. M. (2005). Optimization of fuzzy production inventory model with repairable defective products under crisp or fuzzy production quantity. International Journal of Operations Research, 2 (2), 31-37.
Cheng, F. T., Chang, H. H., Chiu S. W. (2010). Economic Production Quantity Model with Backordering, Rework and Machine Failure Taking Place In Stock Piling Time. WSEAS Transactions On Information Science And Applications, 4 (7), 463-473.

Chiu, S. W., Wang, S.-L., Chiu, Y.-S.P. (2007). Determining the optimal run time for EPQ model with scrap, rework, and stochastic breakdowns. European Journal of Operational Research, 180(2), 664676.

Chiu, S., W., Chen, K-K., Chang, H-H. (2008). Mathematical method for expediting scrap-or-rework decision making in EPQ model with failure in repair. Mathematical and Computational Applications, 13 (3), 137-145.

Chiu, Y. P. (2003). Determining the optimal lot size for the finite production model with random defective rate, the rework process, and backlogging. Engineering Optimization, 35(4), 427-437.

Chui, H. N., Chen, H. M. (2005). An optimal algorithm for solving the dynamic lot-sizing model with learning and forgetting in setups and production. International Journal of Production Economics, 95 (2), 179-193.

Chui, Y. S. P., Lin, H. D., Chang, H. H. (2011). Mathematical Modeling for Solving Manufacturing Run Time Problem with Defective Rate and Random Machine Breakdown. Computers and Industrial Engineering, 60, 576-584.

Chung, K. J. (1998). A Theorem on the Determination of Economic Order Quantity under Conditions of Permissible Delay in Payments. Computers and Operations Research, 25, 49-52.

Chung, K. J., Hou, K. L. (2003). An optimal production run time with imperfect production processes and allowable shortages. Computers and Operations Research, 30, 483-490.

Chung, K. J., Huang, Y. F. (2003). The Optimal Cycle Time for EPQ Inventory Model under Permissible Delay in Payments. International Journal of Production Economics, 84, 307-318.

Darwish, M. (2008). EPQ model with varying setup cost. International Journal of Production Economics, 113, 297-306. 
Dem H., Singh S.R., Kumar J. (2014) An EPQ model with trapezoidal demand and under volume flexibility, International Journal of Industrial Engineering Computations. 5, 127-138.

Dobos, I., Richter, K. (2003). A production/recycling model with stationary demand and return rates. Central European Journal of Operations Research $11(1), 35-46$.

Dobos, I., Richter, K. (2004). An extended production/recycling model with stationary demand and return rates. International Journal of Production Economics 90 (3), 311-323.

Drake, M. J. , Pentico, D. W., Toews, C. (2011). Using the EPQ for Coordinated Planning of a Product with Partial Backordering and its Components. Mathematical and Computer Modelling 53, 359-375.

Eroğlu, A. (2002). Deterministik Envanter Modelleri, Fakülte Kitabevi, 182, Isparta.

Eroğlu, A., Sütçü, A., Sulak, H. (2008). Rassal Olarak Kusurlu Üretim Yapan Üretim Süreçleri İçin Ekonomik Üretim Miktarı Modeli. Gazi Üniversitesi Müh. Mim. Fak. Dergisi, 23, No 4, 923-929.

Ertogral, K. (2011). A Vendor-buyer lot sizing problem with stochastic demand: An exact procedure under service level approach. European Journal of Industrial Engineering, 5/1, 101-110.

Glock C. H., Jaber, M. Y. (2013). An economic production quantity (EPQ) model for a customer-dominated supply chain with defective items, reworking and scrap, International Journal of Services and Operations Management, 14 (2), 236-251.

Hafshejani, K. F., Valmohammadi, C., Khakpoor A. (2012). Retracted: Using genetic algorithm approach to solve a multi-product EPQ model with defective items, rework, and constrained space, Journal of Industrial Engineering International, 8: 27.

Halim, K. A., Giri, B. C., Chaudhuri, K. S. (2009). Fuzzy EPQ models for an imperfect production system. International Journal of Systems Science, 40 (1), 45-52.

Hariga, M. A., Ben-Daya, M. (1996). Optimal Time Varying Lot-Sizing Models under Inflationary Conditions. European Journal of Operational Research, 89, 313-325.
Hariga, M.A. (2010). A single-item continuous review inventory problem with space restriction. International Journal of Production Economics, 128, 153-158

Harris, F.W. (1913). How many parts to make at once. Factory The Magazine of Management, 10, 135-136.

Hayek, P. A., Salameh, M. K. (2001). Production lot sizing with the reworking of imperfect quality items produced. Production Planning and Control, 12(6), 584-590.

Hu, F., Liu, D. (2010). Optimal Replenishment Policy for the EPQ Model with Permissible Delay in Payments and Allowable Shortages. Applied Mathematical Modelling, 34, 3108-3117.

Islam, S., Roy, T. K. (2006). A fuzzy EPQ model with flexibility and reliability consideration and demand dependent unit production cost under a space constraint: A fuzzy geometric approach. Applied Mathematics and Computation, 176, 531-544.

Ittharat T. (2004). The Integrated Economic production Quantity Model for Inventory and Quality, $\mathrm{PhD}$ Thesis in Texas Tech University, pp. 223.

Jaber, M. Y., Bonney, M. (2007). Economic Manufacture Quantity (EMQ) Model with Lot-Size Dependent Learning and Forgetting Rates. International Journal of Production Economics, 108 (1-2), 359367.

Jaber, M. Y., Guiffrida, A. L. (2008). Learning Curves for Imperfect Production Processes with Reworks and Process Restoration Interruptions. European Journal of Operational Research, 189 (1), 93-104.

Jaber, M., Y., Goyal, S. K., Imran, M. (2008). Economic production quantity model for items with imperfect quality subject to learning effects. International Journal of Production Economics, 115, 143-150.

Jaber, M.Y., Bonney, M. (1998). The effects of learning and forgetting on the optimal lot size quantity of intermittent production runs. Production Planning and Control 9 (1), 20-27.

Jaber, M.Y., El Saadany, A. M. A. (2011). An Economic Production and Remanufacturing Model with Learning Effects. International Journal of Production Economics 131, 115-127. 
Karaöz, M. (2003). Öğrenme ve Farklı Talep Fonksiyonlarını İçeren Ekonomik Üretim Miktarı Model Önerileri. Süleyman Demirel Üniversitesi, Yayımlanmamış Doktora Tezi, Isparta, 217s.

Kazemi, N., Ehsani, E., Jaber, M. Y. (2010). An inventory model with backorders with fuzzy parameters and decision variables. International Journal of Approximate Reasoning, 51, 964-972.

Kim, C. H., Hong, Y. (1999). An optimal production run length in deteriorating production processes. International Journal of Production Economics 58, 183-189.

Kobu, B. (2006). Üretim Yönetimi. 13. Baskı, Beta Yay1nevi, $602 \mathrm{~s}$. İstanbul.

Köse, E., Temiz, I., Erol, S. (2011). Grey System Approach for Economic Order Quantity Models under Uncertainty, The Journal of Grey System, 1, 71-82.

Kreng, V. B., Tan, S. J. (2011). Optimal Replenishment Decision in an EPQ Model with Defective Items under Supply Chain Trade Credit Policy. Expert Systems with Applications, 38, 9888-9899.

Kumar, S. A., Suresh, N. (2008). Production and Operations Management. New-Age International Publishers, 2. Bask1, 271 s., Yeni Delhi, Hindistan.

Li, J., Wang, S., Cheng, T. C. E. (2008). Analysis of Postponement Strategy by EPQ-based Models with Planned Backorders. Omega, 36, 777-788.

Liao, G. L., Chen, Y. H., Sheu, S. H. (2009). Optimal Economic Production Quantity Policy for Imperfect Process with Imperfect Repair and Maintenance. European Journal of Operational Research, 195, 348-357.

Liao, G. L., Sheu, S. H. (2011). Economic Production Quantity Model for Randomly Failing Production Process with Minimal Repair and Imperfect Maintenance. International Journal of Production Economics, 130, 118-124.

Liao, J. J. (2007). On an EPQ model for deteriorating items under permissible delay in payments. Applied Mathematical Modelling, 31, 393-403.
Lo, S. T., Wee, H. M., Huang W.C. (2007). An integrated production-inventory model with imperfect production processes and Weibull distribution deterioration under inflation. International Journal of Production Economics, 106, 248-260.

Mahata, G. C. (2012). An EPQ-based inventory model for exponentially deteriorating items under retailer partial trade credit policy in supply chain. Expert Systems with Applications, 39, 3537-3550.

Majumder P., Bera, U.K. (2013). An EPQ-based inventory model for deteriorationg items under stockdependent demand with immediate part payment, Journal of Applied Mathematics and Physics, 1, 2530.

Mondal, S., Maiti, M. (2003). Multi-item fuzzy EOQ models using genetic algorithm. Computers and Industrial Engineering, 44 (1), 105-117.

Monks, J. G. (1996). Operation Managements. Schaum's Outlines, Mc-Graw Hill, 2nd Edition, $427 \mathrm{~s}$.

Mukhopadhyay, A., Goswami, A. (2013). Economic production quantity (EPQ) model for three type imperfect items with rework and learning in setup, International Journal of Optimization \& Control: Theories \& Applications 4 (1), 57-65.

Mula, J., Peidro, D., Poler, R. (2010). The effectiveness of a fuzzy mathematical programming approach for supply chain production planning with fuzzy demand. International Journal of Production Economics, 128, 136-143.

Musa, A., Sani, B. (2012). Inventory Ordering Policies of Delayed Deteriorating Items under Permissible Delay in Payments. International Journal of Production Economics, 136, 75-83.

Nahmias, S. (2009). Production and Operation Analysis. Mc-Graw Hill, 6. Baskı, 790s., ABD.

Nahmias, S., Rivera, H. (1979). A deterministic model for a repairable item inventory system with a finite repair rate. International Journal of Production Research 17 (3), 215-221. 
Ojha, D., Sarker, B. R., Biswas, P. (2007). An optimal batch size for an imperfect production system with quality assurance and rework. International Journal of Production Research, 45:14, 3191-3214.

Pal, B., Sana S. S., Chaudhuri K. (2013). Maximising profits for an EPQ model with unreliable machine and rework of random defective items, International Journal of Systems Science, 44 (3), 582-594.

Pal, S., Maiti, M. K., Maiti, M. (2009). An EPQ model with price discounted promotional demand in an imprecise planning horizon via Genetic Algorithm. Computers and Industrial Engineering, 57 (1), 181-187.

Pan, J.C.-H., Yang, M.-F. (2008). Integrated inventory models with fuzzy annual demand and fuzzy production rate in a supply chain. International Journal of Production Research, 46(3), 753-770.

Pasandideh, S. H. R., Niaki, S. T. A. (2008). A genetic algorithm approach to optimize a multi-products EPQ model with discrete delivery orders and constrained space. Applied Mathematics and Computation, 195, 506-514.

Pentico, D. W., Drake, M. (2011). A survey of deterministic models for the EOQ and EPQ with partial backordering. European Journal of Operational Research, 214 (2), 179-198.

Pentico, D. W., Matthew, J. D., Toews, C. (2009). The deterministic EPQ with partial backordering: a new approach. Omega, 37, 624-636.

Raafat, F. (1991). Survey of literature on continuosly deteiorating inventory models. Journal of Operational Research Society, 42 (1), 27-37.

Richter, K. (1996a). The extended EOQ repair and waste disposal model. International Journal of Production Economics, 45 (1-3), 443-447.

Richter, K. (1996b). The EOQ and waste disposal model with variable setup numbers. European Journal of Operational Research 95 (2), 313-324.

Richter, K. (1997). Pure and mixed strategies for the EOQ repair and waste disposal problem. OR Spectrum 19 (2), 123-129.
Roy, A., Maity, K., Kar, S., Maiti, M. (2009). A production-inventory model with remanufacturing for defective and usable items in fuzzy-environment. Computers and Industrial Engineering, 56, 87-96.

Salameh, M. K., Jaber, M. Y. (2000). Economic production quantity model for items with imperfect quality. International Journal of Production Economics, 64, 59-64.

Sana S. S. (2008). An EOQ model with a varying demand followed by advertising expenditure and selling price under permissible delay in payments: for a retailer, International Journal of Modelling, Identification and Control, 5 (2), 166-172.

Sana, S. S. (2010). An economic production lot size model in an imperfect production system. European Journal of Operational Research, 201, 158-170.

Sarkar B., Sana S. S., Chaudhuri K. (2011). An imperfect production process for time varying demand with inflation and time value of Money - An EMQ model. Expert System with Applications, 38 (11), 13543-13548.

Schrady, D.A. (1967). A deterministic inventory model for repairable items. Naval Research Logistics 14 (3), 391-398.

Schuh, G. (2008). Produktionsmanagements I, WZL/ FIR, Aachen Universitat.

Singh C., Singh S.R. (2011). Imperfect production process with exponantial demand rate, Weibull deterioration under inflation. International Journal of Operational Research, 12 (4), 430-445.

Stojkovska I. (2013). On the optimality of the optimal policies for the deterministic EPQ with partial backordering, Omega, 41 (5), 919-923.

Sulak, H., Eroğlu A. (2009). Ekonomik sipariş ve üretim miktarı modellerinde yeni açılımlar. Süleyman Demirel Üniversitesi İktisadi ve İdari Bilimler Fakültesi Dergisi, 14 (3), 383-406.

Taft, E. W. (1918). The Most Economical Production Lot. Iron Age, 101, 140-1412. 
Taleizadeh, A. A., Cardenas-Barron L. E., Mohammadi B. (2013). A deterministic multi product single machine EPQ model with backordering, scraped products, rework and interruption in manufacturing process, International Journal of Production Economics, 150, 9-27.

Teng J.T., Chang C.T. (2005). Economic production quantity models for deteriorating iitems with price and stock dependent demand. Computer and Operations Research 32, 297-308.

Teng J.T., Ouyang L.Y., Chang C.T. (2005). Deterministic economic production quantity models with time-varying demand and cost. Applied Mathematical Modelling 29, 987-1003.

Teng, J. T., Chang, C. T. (2009). Optimal Manufacturer's Replenishment Policies in the EPQ Model under Two Levels of Trade Credit Policy. European Journal of Operational Research, 195, 358-363.

Tersine, R. J. (1994). Principles of Inventory and Materials Management. Printice Hall, 4th Edition, 591 s. ABD.

Teunter, R. H. (2001). Economic ordering quantities for recoverable item inventory systems. Naval Research Logistics 48 (6), 484-495.

Toews, C., Pentico, D. W., Drake, M. J. (2011). The deterministic EOQ and EPQ with partial backordering at a rate that is linearly dependent on the time to delivery. International Journal of Production Economics, 131, 643-649.

Wee H. M., Widyadana G. A. (2012). Economic production quantity models for deteriorating items with rework and stochastic preventive maintenance time. International Journal of Production Research, 50 (11), 2940-2952.
Wee H.-M., Wang, W.-T., Yang, P.-C. (2013). A production quantity model for imperfect items with shortage and screening constraint, International Journal of Production Research, 51 (6), 1869-1884.

Yang, L., Yang, J., Gang, Y., Zhang, H. (2011). Nearoptimal (r,Q) Policies for a Two-stage Serial Inventory System with Poisson Demand. International Journal of Production Economics,133, 728-735.

Yenersoy, G. (2011). Üretim Planlama ve Kontrol. Papatya Yayınları, 383 s., İstanbul, Türkiye.

Yoo, S. H., Kim, D., Park, M. S. (2009). Economic Production Quantity Model with Imperfect Quality Items, Two-way Imperfect Inspection and Sales Return. International Journal of Production Economics, 121, 255-265.

Yüksel, H. (2010). Üretim/İşlemler Yönetimi Temel Kavramlar. 2. Baskı, Nobel Yayın Dağıtım, No:1368, 388 s. Ankara.

Zhang, R. (2009). A note on the deterministic EPQ with partial backordering. Omega, 37, 1036-1038.

Zhang, R.-Q., Kaku, I., Xiao, Y.-Y. (2011). Deterministic EOQ with partial backordering and correlated demand caused by cross-selling. European Journal of Operational Research, 210 (3), 537-551.

Zhao, P., Wang, H., Gao, H. (2006). Improved particle swarm optimization algorithm for stochastic EOQ models with multi-item and multi-storehouse. Proceedings of the IEEE International Conference on Information Acquisition, August 20-23, Welhal, Shandong, China. 